Article

\title{
Terahertz Displacement and Thickness Sensor with Micrometer Resolution and Centimeter Dynamic Range
}

\author{
Dae-Hyun Han ${ }^{1}$ and Lae-Hyong Kang ${ }^{2, *(1)}$ \\ 1 Department of Mechatronics Engineering, and LANL-JBNU Engineering Institute-Korea, Jeonbuk National \\ University, 567 Baekje-daero, Duckjin-gu, Jeonju-si, Jeonbuk 54896, Korea; dh.han@jbnu.ac.kr \\ 2 Department of Mechatronics Engineering, Department of Flexible and Printable Electronics, \\ and LANL-JBNU Engineering Institute-Korea, Jeonbuk National University, 567 Baekje-daero, Duckjin-gu, \\ Jeonju-si, Jeonbuk 54896, Korea \\ * $\quad$ Correspondence: reon.kang@jbnu.ac.kr; Tel.: +82-632-703-372
}

Received: 31 October 2019; Accepted: 27 November 2019; Published: 29 November 2019

check for updates

\begin{abstract}
Measuring distance and thickness simultaneously is important in biological, medical, electronic, and various industries. Herein, we propose a method for simultaneously measuring the displacement and thickness of transparent materials using a pulsed terahertz wave. For this technique, a beam splitter was used to design the optical path such that the terahertz wave would incident the specimen vertically to achieve centimeter measurement range and micrometer resolution. The measured terahertz waveform carries peak time information reflected from the upper and lower surfaces of the sample, and the thickness can be calculated using the time difference between the first and second reflected peaks. The displacement can also be calculated using peak time difference when the sample moves from the initial position to the changed position. For validation, an experimental test was performed using aluminum, acrylic, and glass plates. The results confirmed a measurement range of $1 \mathrm{~cm}$ with an error of less than $23 \mu \mathrm{m}$, and the thickness error was less than $8 \mu \mathrm{m}$.
\end{abstract}

Keywords: centimeter dynamic range; displacement; sensor; terahertz; thickness; transparency

\section{Introduction}

Terahertz (THz) waves, whose portion of the electromagnetic spectrum extends from $100 \mathrm{GHz}$ to $10 \mathrm{THz}$, have attracted extensive interest in recent years and have been widely used in a range of engineering fields [1-7], such as material characteristics analysis [1,2,4], testing of pharmaceutical tablet properties [2,5], and gas [6,7]. Compared with conventional sensing technologies, THz waves have numerous attractive spectral features associated with fundamental physical processes, such as a large amplitude in vibrational motions of organic compounds, rotational transition levels of molecules, lattice vibrations in solids, intra-band transitions in semiconductors, and energy gaps in superconductors [8]. One $\mathrm{THz}$ application is in simultaneously measuring the displacement and thickness of a sample (regardless of its transparency) in nonconductive materials. Non-contact displacement sensors [9-13] with micrometer resolution and centimeter operational range have been increasingly used for demanding measurement tasks involving highly sensitive surfaces to control precise movements or monitor target positions. A displacement sensor that uses a light source $[9,10]$ is limited in measuring the displacement of transparent objects, but it can measure the spot region of a sample. Displacement sensors using eddy currents $[11,12]$ can only measure displacement when measuring a sample on metal substrates, while ultrasonic displacement sensors [13] can measure displacement regardless of the substrate. Conversely, eddy current and ultrasonic displacement sensors have limitations 
in displacement measurement when they measure the spot region of a sample. Eddy current [14] and ultrasonic [15] thickness sensors used for engineering thick samples (above $100 \mu \mathrm{m}$ ) require direct contact between the sensor and sample surface. Most existing non-contact methods are capable of thickness measurements in the wavelength range of visible light and are effective with transparent solid-state and relatively stiff samples. However, it remains a challenge for full-field thickness measurements at the micrometer and centimeter dynamic range, regardless of the transparency of the materials. Another method for thickness measurements involves the use of $\mathrm{THz}$ waves. Terahertz-based thickness measurement methods have recently been introduced as a technology for measuring the thickness of various sample types. Yasui et al. [16] demonstrated a terahertz "paint meter" for non-contact thickness mapping of multilayer paints with relatively thick film builds (above $100 \mathrm{~m}$ ). Yasuda et al. [17] proposed a numerical parameter fitting method that increases the sensitivity of the minimum thickness measurement. Su et al. [18] proposed the use of terahertz pulsed imaging as a novel tool for measuring the thickness and quality of car paint on both metallic and nonmetallic substrates. Han et al. [19] demonstrated a thickness measurement of the multi-delamination in glass-fiber-reinforced plastic (GFRP) using pulsed THz waves.

In this paper, a THz displacement and full-field thickness sensor is proposed to achieve high micrometer resolution and a centimeter dynamic range based on the excellent reflection and transmission properties of $\mathrm{THz}$ waves. The $\mathrm{THz}$ sensor was designed to propagate perpendicularly to the surface of the sample by employing a $\mathrm{THz}$ beam splitter. This configuration can achieve wider displacement and thickness measurement ranges of up to $10 \mathrm{~mm}$ and $5 \mathrm{~mm}$, respectively. In the following section, we describe the principle and experimental setup of the method, followed by validation and an example application.

\section{Measurement Principles and Setup}

The method reported herein for displacement and thickness measurement-regardless of the material transparency-is based on the characteristics of pulsed $\mathrm{THz}$ waves. In the case of the thickness measurement, only nonmetallic materials can be used. When pulsed $\mathrm{THz}$ waves are incident on a sample, reflections arise in the $\mathrm{THz}$ waveform due either to the interface between different mediums or to the extinction coefficient of metallic materials. The first reflected $\mathrm{THz}$ waves rise due to the interface between free space (air, $n_{\text {air }}=1$ ) and the sample surface. The refractive index of the sample is generally greater than that of air, so a positive peak is observed in the $\mathrm{THz}$ waveform. The negative peak is observed when the refractive index of the preceding medium is greater than that of the incident medium. In the case of metal surfaces, the positive peak is always observed due to the extinction coefficient of metallic materials [18].

\subsection{Measurement of the Displacement and the Thickness}

The time-resolved detection scheme of THz-TDS (Terahertz Time-Domain Spectroscopy) is directly applicable to measuring the displacement information of multilayer samples. When pulsed $\mathrm{THz}$ waves are incident on a nonmetallic sample, regardless of the transparency, the reflected $\mathrm{THz}$ waveform consists of a series of pulses reflected from the interface. The displacement of the sample can then be calculated in the $\mathrm{THz}$ reflection mode using the following equation:

$$
D_{\text {sample }}=\frac{\left|t_{\text {zero }}-t_{\text {sample }}\right|}{2} \times \frac{c}{n_{\text {air }}} \times \cos \theta,
$$

where $D_{\text {sample }}$ represents the sample displacement, $t_{\text {zero }}$ is the peak time measured at the initial position of the sample, $t_{\text {sample }}$ is the peak time measured at the moving position of the sample, $c$ is the speed 
of light in air, and $n_{\text {air }}$ is the refractive index of air. The thickness of the sample or defect can also be calculated in the $\mathrm{THz}$ reflection scan mode via the following equation:

$$
T_{\text {sample }}=\frac{\Delta t}{2} \times \frac{c}{n_{\text {sample }}} \times \cos \theta,
$$

where $T_{\text {sample }}$ represents the sample thickness, $\Delta t$ is the time between successive reflections, $c$ is the speed of light in air, and $n_{\text {sample }}$ is the refractive index of the sample; the factor of one-half arises as the $\mathrm{THz}$ waves are measured in reflection mode.

\subsection{Design of the THz Displacement and Thickness Sensor}

The test setup and schematic diagram for the proposed $\mathrm{THz}$ displacement and thickness sensor is shown in Figure 1a,b, respectively. The sensor mainly consists of a femtosecond laser (T-Light, Menlo Systems Corp., Planegg, Germany) with a $1560 \pm 20 \mathrm{~nm}$ wavelength and $100 \pm 1 \mathrm{MHz}$ repetition rate, optical delay unit (ODU; Menlo Systems Corp., Planegg, Germany), photoconductive antenna (PCA) for the emitter and detector, motorized linear stage (M-403.6PD, PI Corp., Auburn, MA, USA), data acquisition (DAQ; NI Corp., Austin, TX, USA), and THz optics including a TPX (Polymethyl Pentene) lens (for collimation or focusing) and beam splitter. The motorized linear stage is used to compare the performance of the $\mathrm{THz}$ displacement sensor and commercial displacement sensor based on a laser triangulation method in the centimeter range.

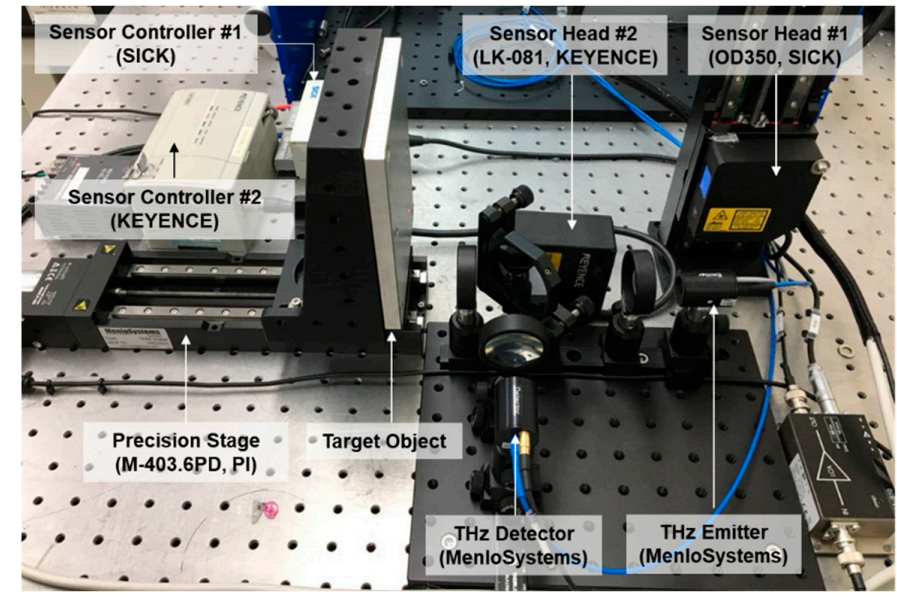

(a)

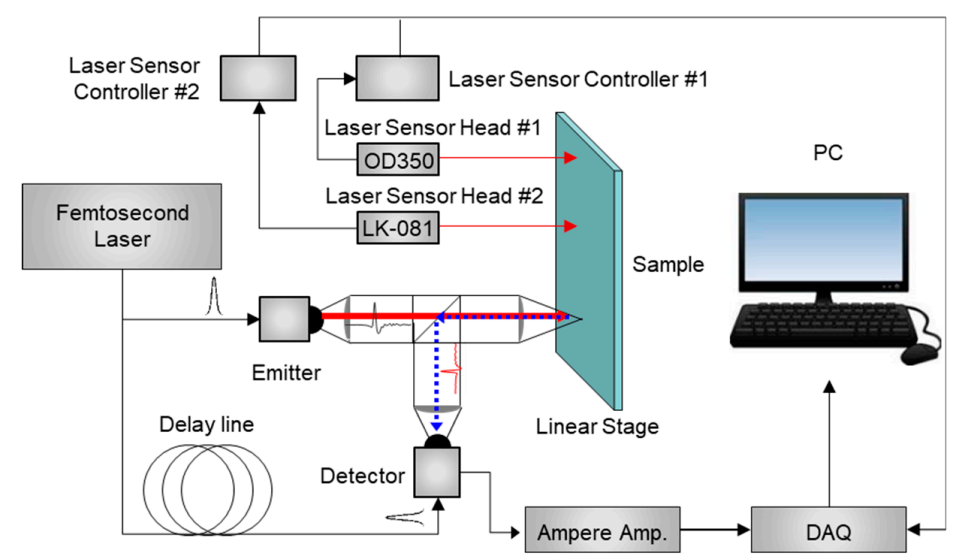

(b)

Figure 1. Terahertz (THz) displacement and thickness sensor: (a) experimental test setup; (b) schematic diagram. 
The optical path of the $\mathrm{THz}$ displacement and thickness sensor was designed such that the pulsed THz waves are incident perpendicular to the surface of the sample to achieve the centimeter measurement range, as shown in Figure 2. In brief, separated pulsed laser light with femtosecond pulse width supplies the THz emitter and a detector through the ODU. The emitted THz waves are collimated after passing through a TPX lens and then separated by a THz beam splitter, where $60 \%$ travels along the designed optical path and $40 \%$ enters the free space. The pulsed $\mathrm{THz}$ waves are focused on the sample surface after passing through a TPX lens. Subsequently, the THz waves reflected at the air-sample interface (such as the interface of different medium) are focused onto the THz detector. The reflected pulsed $\mathrm{THz}$ waves are collimated after passing through a TPX lens and reflected $90^{\circ}$ toward the $\mathrm{THz}$ detector by the beam splitter.

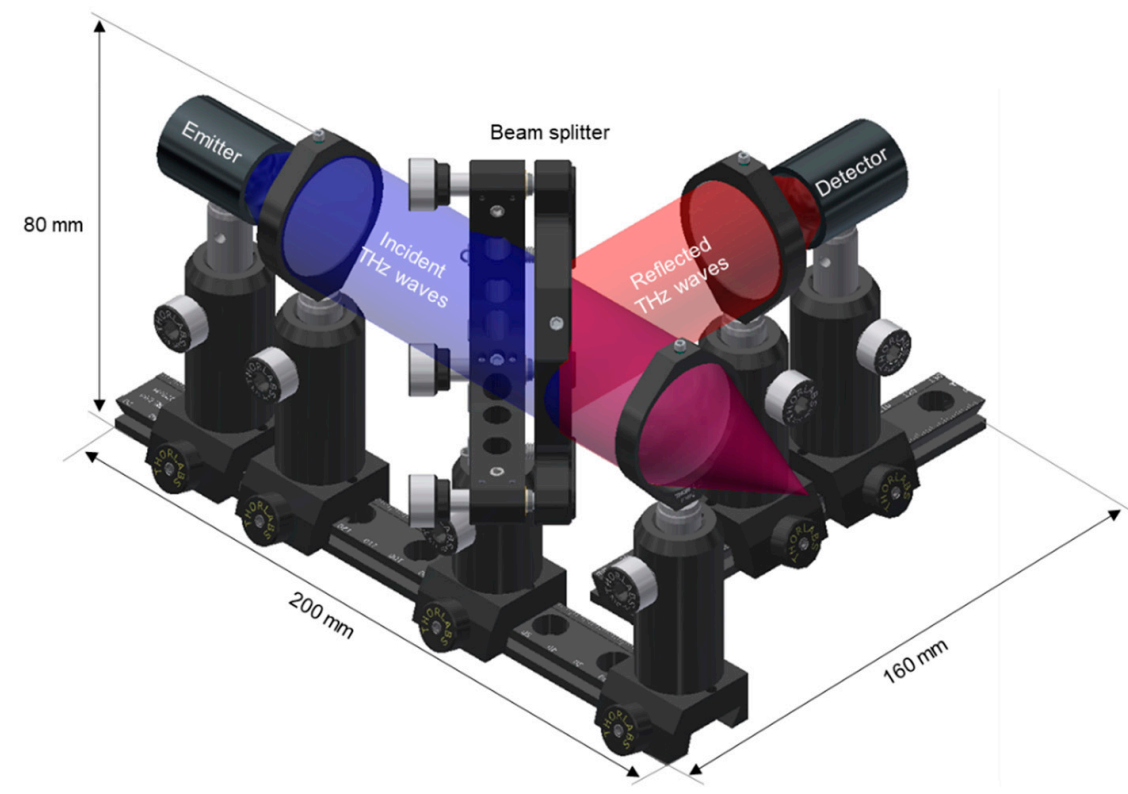

Figure 2. Designed optical path for the THz displacement and thickness sensor.

\section{Experiments and Applications}

\subsection{Displacement Measurement Range Performance Comparison}

The performance of the proposed $\mathrm{THz}$ displacement sensor was compared with an OD350 laser displacement sensor (range: $250 \mathrm{~mm}$; resolution: $200 \mu \mathrm{m}$; SICK Corp., Waldkirch, Germany) for long-range measurement and with an LK-081 laser displacement sensor (range: $\pm 15 \mathrm{~mm}$; resolution: $3 \mu \mathrm{m}$; KEYENCE Corp., Osaka, Japan) for high accuracy measurement resolution with short measurement range. An aluminum plate was placed vertically on the motorized linear stage, and each $\mathrm{THz}$ displacement sensor was placed on the optical table, as shown in Figure 1a, to measure the displacement exerted on the sample. The displacement inputs were implemented within the range of $0-10 \mathrm{~mm}$. The sample displacement was controlled using the motorized linear stage in $50 \mu \mathrm{m}$ increments over a range of $10 \mathrm{~mm}$. Next, the impact of sample transparency on sensor performance was evaluated by changing the sample material from an aluminum to a glass and acrylic plate.

Figure 3 shows the displacement measurement range results according to commercial Laser Displacement Sensor \#1 (OD350, SICK Corp., Waldkirch, Germany), \#2 (LK-081, KEYENCE Corp., Osaka, Japan), and the proposed $\mathrm{THz}$ displacement sensor. The proposed sensor produced measurement results similar to those of the commercial sensors. In the case of a displacement sensor using a laser source, it is impossible to measure the displacement of a transparent sample. However, the THz displacement sensor can measure not only the displacement of transparent materials (such as glass or acrylic plates) but also metallic materials (such as aluminum plates) with centimeter measurement range, as shown in Figure 4. 


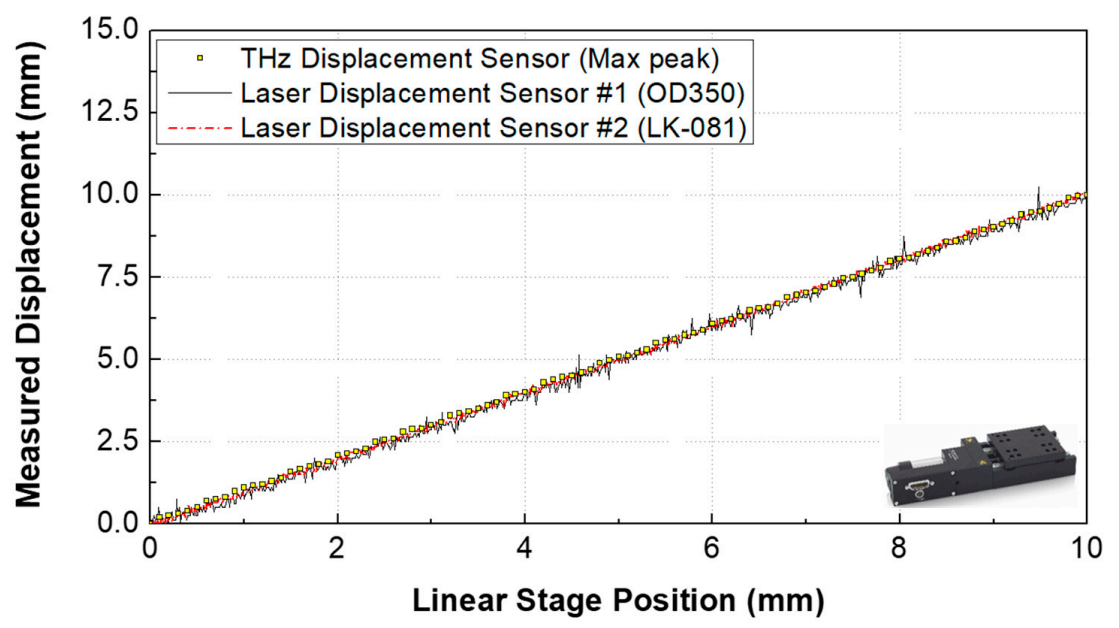

Figure 3. Displacement results according to the two laser displacement sensors and the proposed $\mathrm{THz}$ displacement sensor.

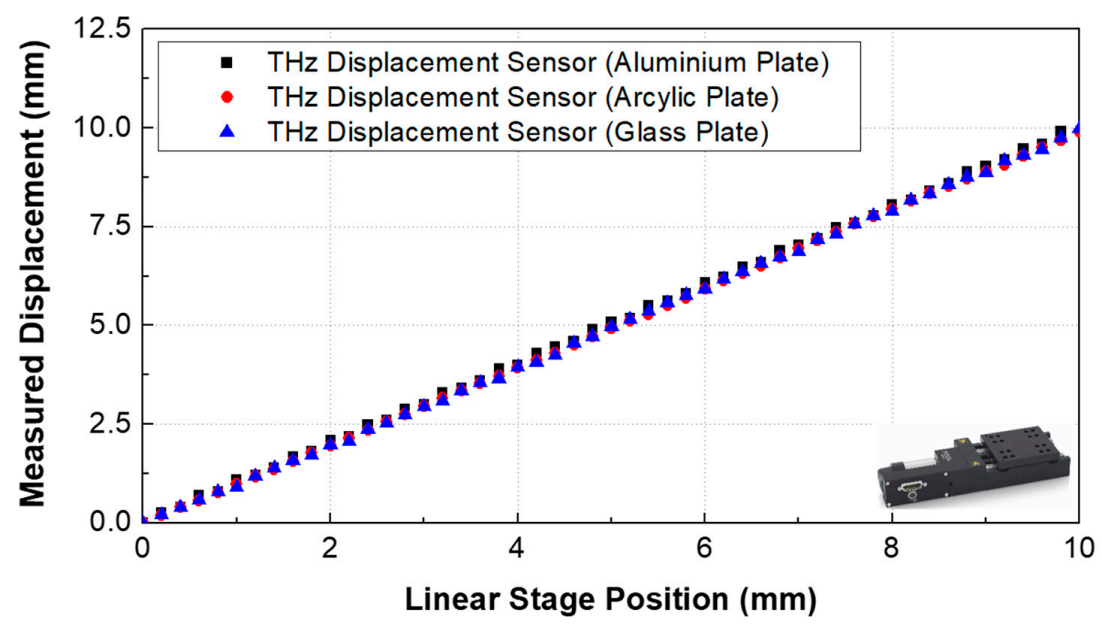

Figure 4. Displacement results for each target material using the $\mathrm{THz}$ displacement sensor.

\subsection{Measurement Accuracy Evaluation of the THz Displacement Sensor}

The displacement of a manual-stage-mounted sample was controlled from 0 to $10 \mathrm{~mm}$ in $2.5 \mathrm{~mm}$ increments $(0,2.5,5.0,7.5$, and $10.0 \mathrm{~mm})$ to evaluate the measurement accuracy. At each position, the precision resolution of the $\mathrm{THz}$ displacement sensor was considered by increasing the displacement in $10 \mu \mathrm{m}$ increments using a manual stage ( $5 \mu \mathrm{m}$ resolution). The detailed conditions and comparison results are summarized in Table 1 . Figure 5 shows the measured displacement and magnitude according to the displacement of the manual stage. The measured displacement linearly increased corresponding to the distance of the manual stage. The magnitude of the maximum peak was constant up to $2.5 \mathrm{~mm}$ and then decreased to $5 \mathrm{~mm}$. The measurement error was calculated, and the results are illustrated in Figure 6. The distance error was less than $\pm 10 \mu \mathrm{m}$ based on the measured value-regardless of the sample material—for the entire measurement range, but the error of the measured displacement increased from 5 to $10 \mathrm{~mm}$, as shown in Figure 6c-e.

The reason for this increase can be attributed to the depth of focus of the plano-convex lens. In this study, we used a plano-convex lens (TPX lens) with $50 \mathrm{~mm}$ focusing length. The depth of focus can be calculated using the following equation [20]:

$$
2 z_{0}=\frac{8}{\pi} \times \frac{c}{f} \times\left(\frac{f_{L}}{D}\right)^{2}
$$


where $z_{0}$ represents the Rayleigh range (the depth of focus is two times the Rayleigh range), $c$ is the speed of light in air $(299,792,458 \mathrm{~m} / \mathrm{s}), f_{L}$ is the effective focal length $(50 \mathrm{~mm})$, and $D$ is the diameter of the TPX lens. As such, the depth of focus can be calculated as $7.6 \mathrm{~mm}(@ 0.1 \mathrm{THz})$ to $0.76 \mathrm{~mm}$ (@ $1.0 \mathrm{THz}$ ). This means that the effective focusing distance is $46.2-53.8 \mathrm{~mm} @ 0.1 \mathrm{THz}$. As a result, not only did the magnitude of the peak point decrease, as shown in Figure 5, but also the error of the distance increased beyond the $5 \mathrm{~mm}$ distance, as shown in Figure 6.

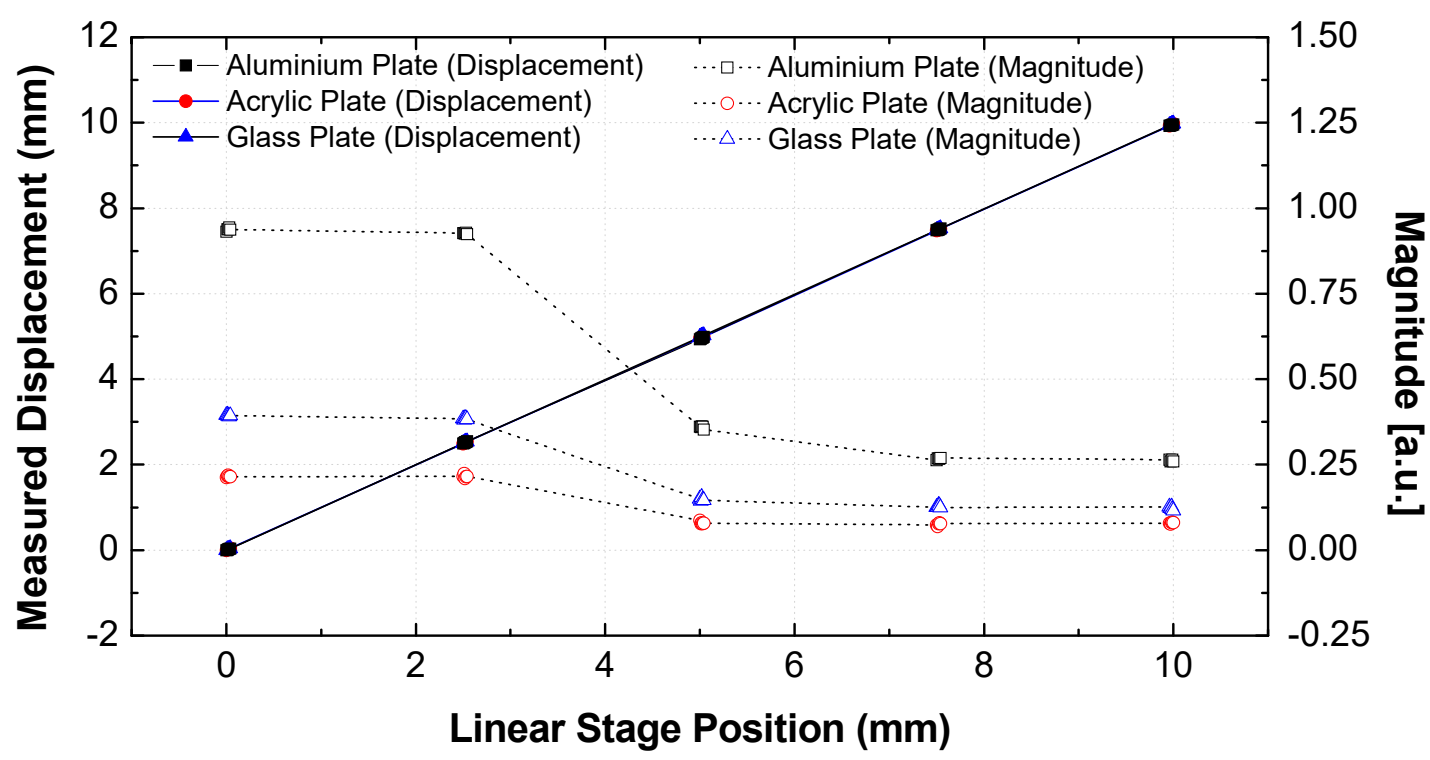

Figure 5. Measured displacement and magnitude of $\mathrm{THz}$ waveform according to target material.

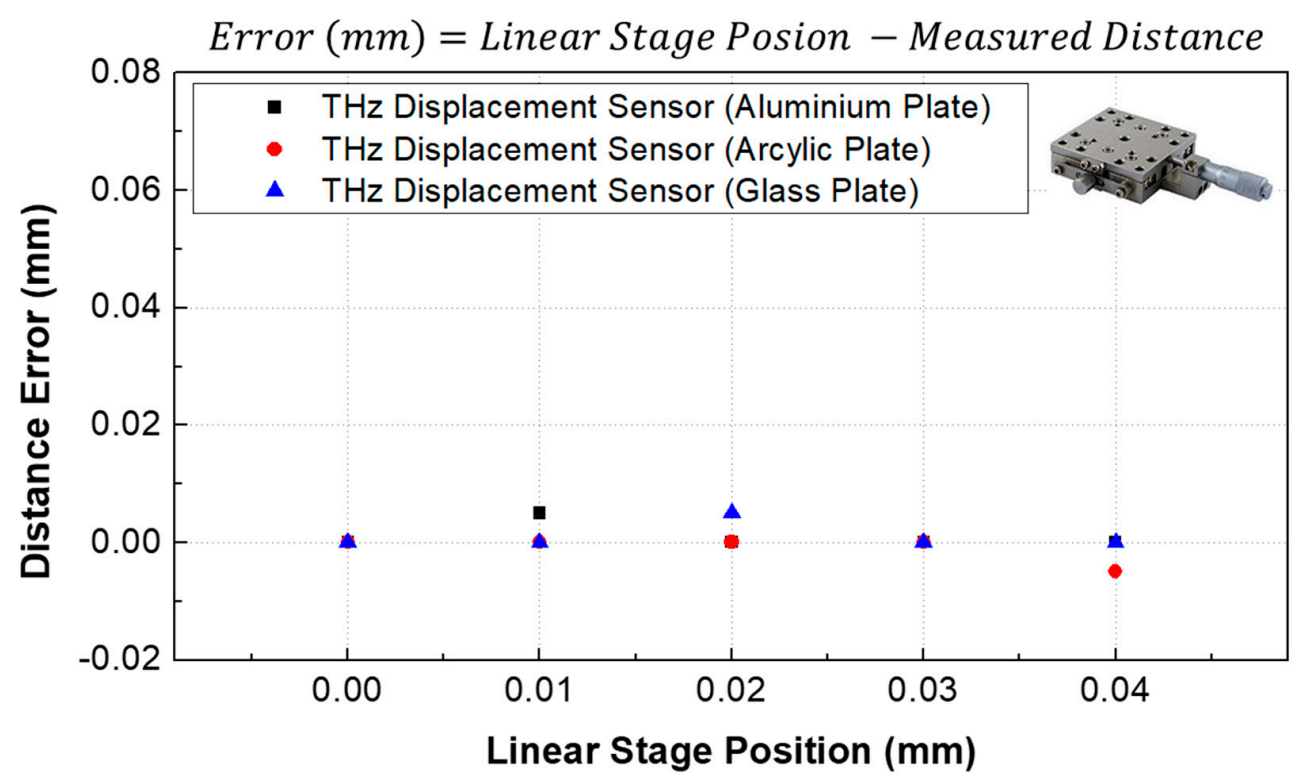

(a)

Figure 6. Cont. 


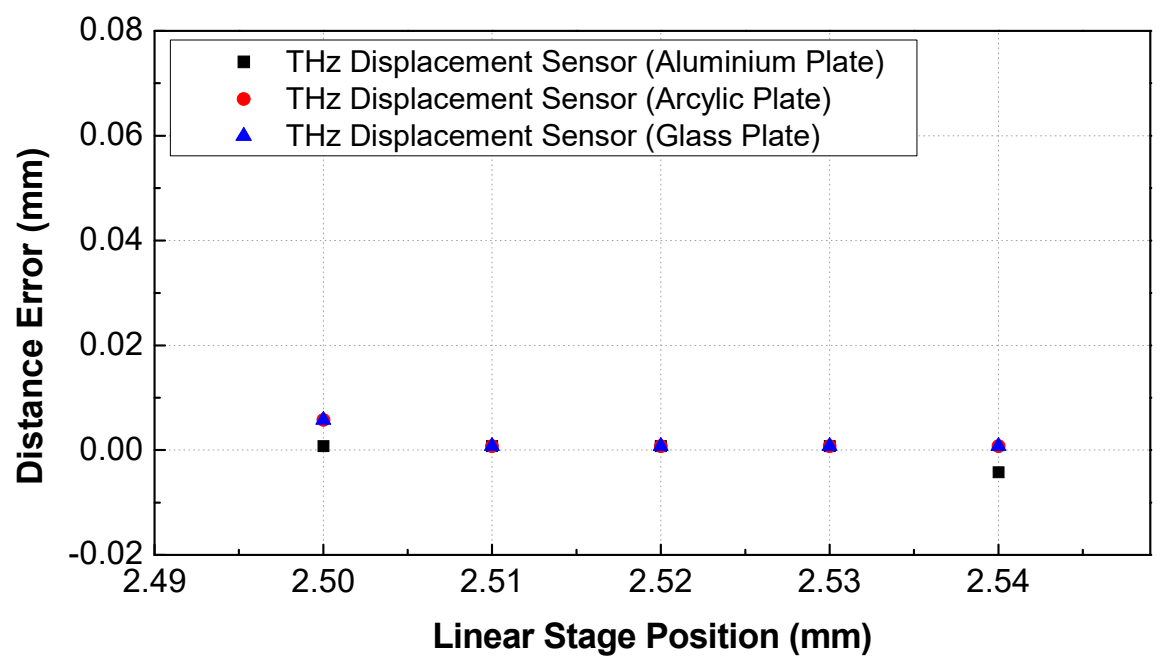

(b)

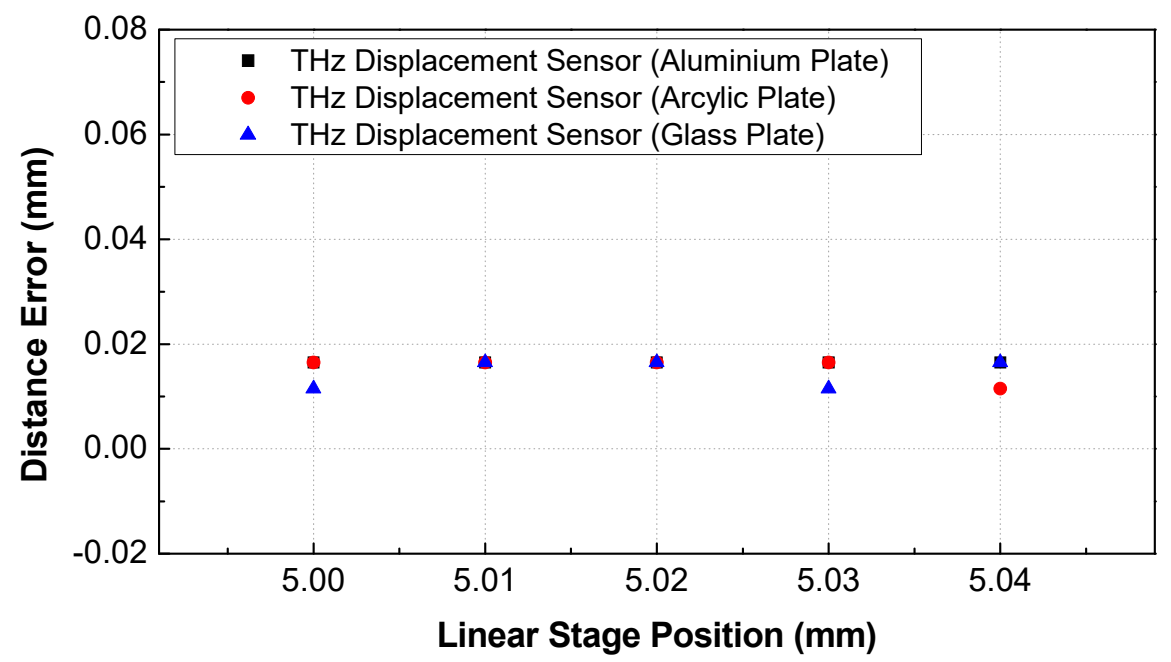

(c)

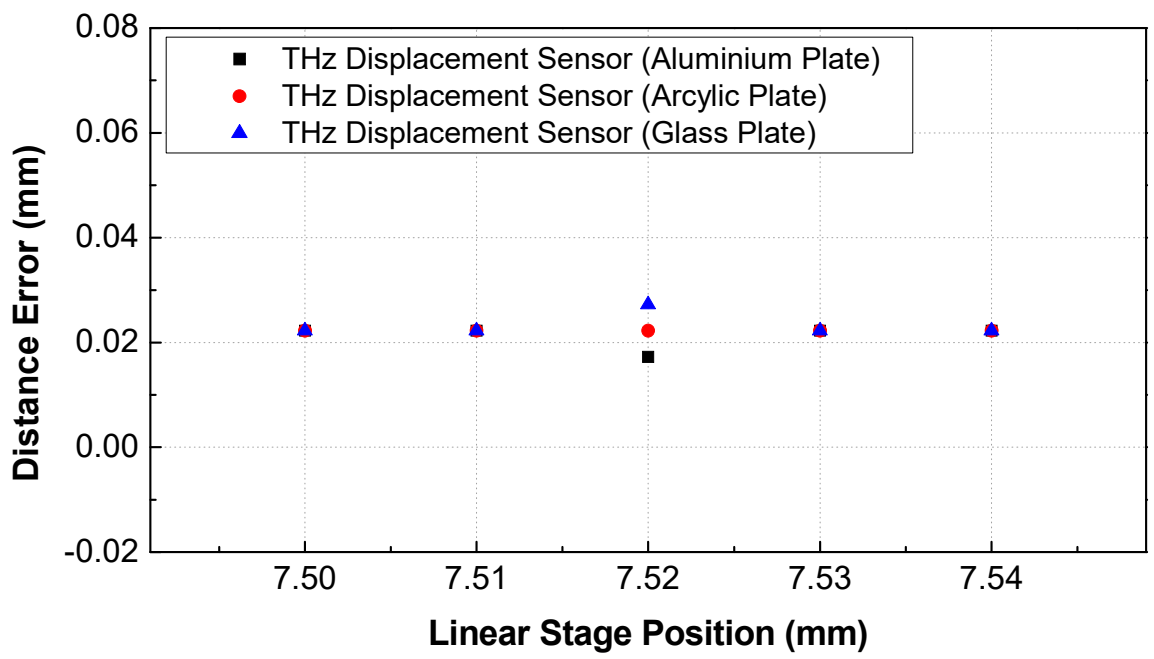

(d)

Figure 6. Cont. 


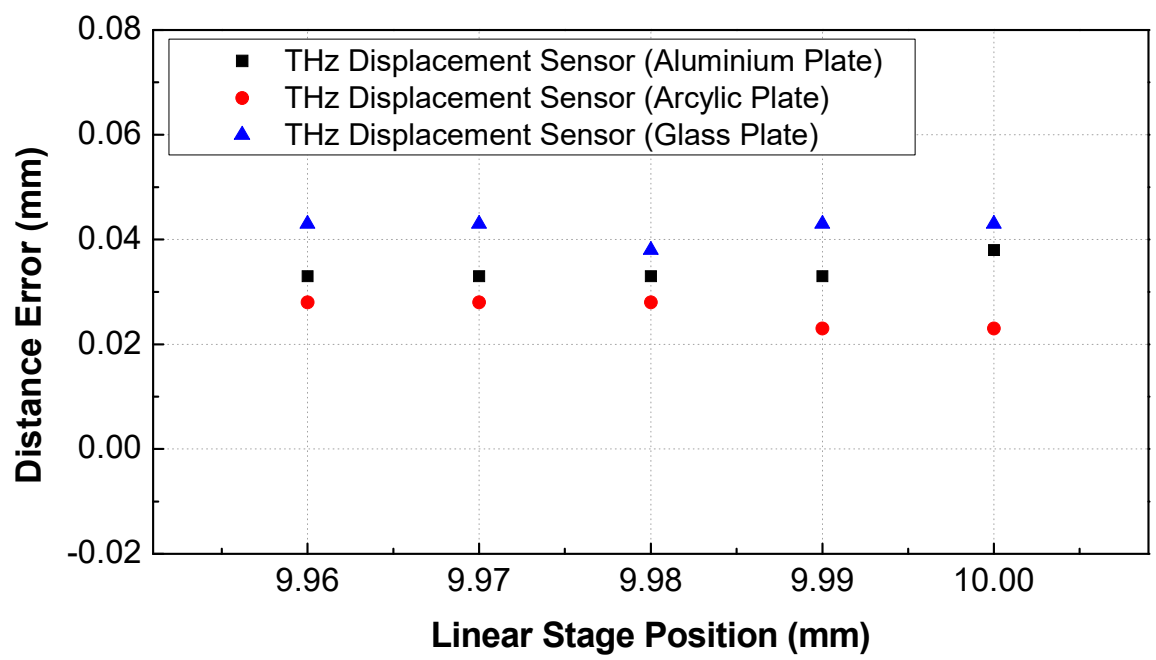

(e)

Figure 6. Measured displacement error according to target materials with centimeter measurement range: (a) 0.00-0.04 mm; (b) 2.50-2.54 mm; (c) 5.00-5.04 mm; (d) 7.50-7.54 mm; (e) 9.96-10.00 mm.

Table 1. Measured displacement results using the $\mathrm{THz}$ sensor.

\begin{tabular}{|c|c|c|c|c|c|c|}
\hline \multirow{2}{*}{ Stage Disp.(mm) } & \multicolumn{3}{|c|}{ Measured Displacement (mm) } & \multicolumn{3}{|c|}{ Displacement Error (mm) } \\
\hline & Aluminum & Acrylic & Glass & Aluminum & Acrylic & Glass \\
\hline 0.00 & 0.000 & 0.000 & 0.000 & 0.000 & 0.000 & 0.000 \\
\hline 0.01 & 0.005 & 0.010 & 0.010 & 0.005 & 0.000 & 0.000 \\
\hline 0.02 & 0.020 & 0.020 & 0.020 & 0.000 & 0.000 & 0.000 \\
\hline 0.03 & 0.030 & 0.030 & 0.030 & 0.000 & 0.000 & 0.000 \\
\hline 0.04 & 0.040 & 0.045 & 0.040 & 0.000 & -0.005 & 0.000 \\
\hline 2.50 & 2.499 & 2.494 & 2.499 & 0.001 & 0.006 & 0.001 \\
\hline 2.51 & 2.509 & 2.509 & 2.509 & 0.001 & 0.001 & 0.001 \\
\hline 2.52 & 2.519 & 2.519 & 2.519 & 0.001 & 0.001 & 0.001 \\
\hline 2.53 & 2.529 & 2.529 & 2.529 & 0.001 & 0.001 & 0.001 \\
\hline 2.54 & 2.544 & 2.539 & 2.539 & -0.004 & 0.001 & 0.001 \\
\hline 5.00 & 4.939 & 4.959 & 4.984 & 0.017 & 0.017 & 0.017 \\
\hline 5.01 & 4.954 & 4.969 & 4.994 & 0.017 & 0.017 & 0.017 \\
\hline 5.02 & 4.964 & 4.979 & 5.009 & 0.017 & 0.017 & 0.012 \\
\hline 5.03 & 4.974 & 4.989 & 5.014 & 0.017 & 0.017 & 0.017 \\
\hline 5.04 & 4.989 & 4.994 & 5.023 & 0.017 & 0.012 & 0.017 \\
\hline 7.50 & 7.483 & 7.478 & 7.483 & 0.022 & 0.022 & 0.017 \\
\hline 7.51 & 7.493 & 7.488 & 7.493 & 0.022 & 0.022 & 0.017 \\
\hline 7.52 & 7.503 & 7.498 & 7.503 & 0.017 & 0.022 & 0.017 \\
\hline 7.53 & 7.513 & 7.508 & 7.513 & 0.022 & 0.022 & 0.017 \\
\hline 7.54 & 7.523 & 7.518 & 7.523 & 0.022 & 0.022 & 0.017 \\
\hline 9.96 & 9.927 & 9.932 & 9.937 & 0.033 & 0.028 & 0.023 \\
\hline 9.97 & 9.937 & 9.942 & 9.947 & 0.033 & 0.028 & 0.023 \\
\hline 9.98 & 9.947 & 9.952 & 9.962 & 0.033 & 0.028 & 0.018 \\
\hline 9.99 & 9.957 & 9.967 & 9.967 & 0.033 & 0.023 & 0.023 \\
\hline 10.00 & 9.962 & 9.977 & 9.977 & 0.038 & 0.023 & 0.023 \\
\hline
\end{tabular}

\subsection{Simultaneous Displacement and Thickness Measurement}

One of the goals of this study was the simultaneous measurement of the displacement and thickness of a transparent sample. Three samples were used to verify the effect of displacement from the zero position on the thickness measurement: an aluminum plate, an acrylic plate of $5 \mathrm{~mm}$ thickness, 
and a glass plate of $1.42 \mathrm{~mm}$ thickness, as summarized in Table 2. The displacement of the samples was controlled from 0 to $2.5 \mathrm{~mm}$. Figure 7 shows the measured $\mathrm{THz}$ waveforms according to sample material at 0 and $2.5 \mathrm{~mm}$ displacements of the sample. Figure $7 \mathrm{a}, \mathrm{c}$ and e show the thickness of the sample at the $0 \mathrm{~mm}$ stage position, while Figure $7 \mathrm{~b}$, d,e show the same at the $2.5 \mathrm{~mm}$ stage position. When the displacement changed from 0 to $2.5 \mathrm{~mm}$, the measured displacement was $2.503 \mathrm{~mm}$ and $2.496 \mathrm{~mm}$ for the acrylic and glass plate, respectively. The thickness of the acrylic plate changed slightly from 4.996 to $4.992 \mathrm{~mm}$, while that of the glass plate changed from 1.420 to $1.417 \mathrm{~mm}$. The thickness of the aluminum plate could not be measured due to the conductivity of the material. Based on a comparison of these results with those of a thickness gauge, the thickness measurement accuracy was found to be within $8 \mu \mathrm{m}$.

Table 2. Measured thickness of the transparent materials using a THz sensor.

\begin{tabular}{lccc}
\hline \multirow{2}{*}{ Target Materials } & \multicolumn{2}{c}{ Thickness (mm) } \\
\cline { 3 - 4 } & & THz Thickness Sensor & Thickness Gauge \\
\hline \multirow{2}{*}{ Acrylic plate } & at $0 \mathrm{~mm}$ & 4.996 & 5.000 \\
& at $2.5 \mathrm{~mm}$ & 4.992 & \multirow{2}{*}{1.420} \\
\hline \multirow{2}{*}{ Glass plate } & at $0 \mathrm{~mm}$ & 1.420 & \\
& at $2.5 \mathrm{~mm}$ & 1.417 & \\
\hline
\end{tabular}

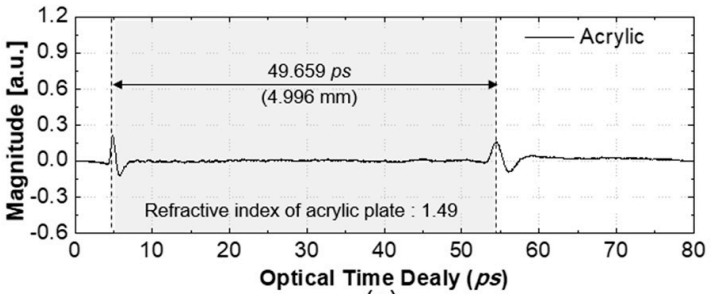

(a)

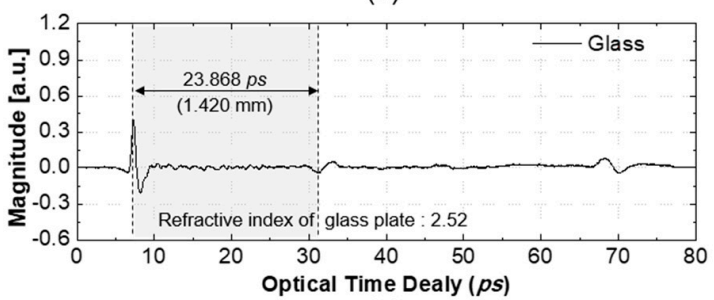

(c)

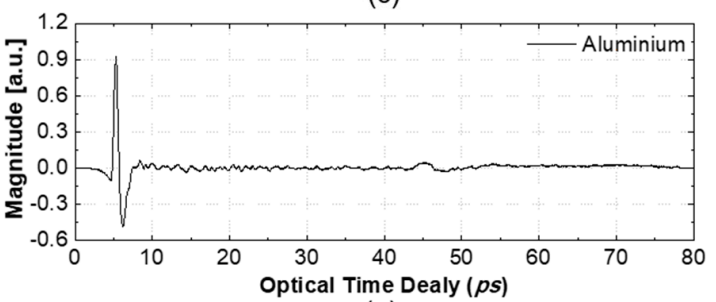

(e)

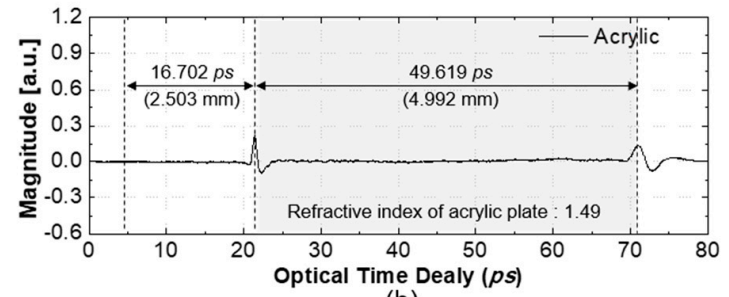

(b)

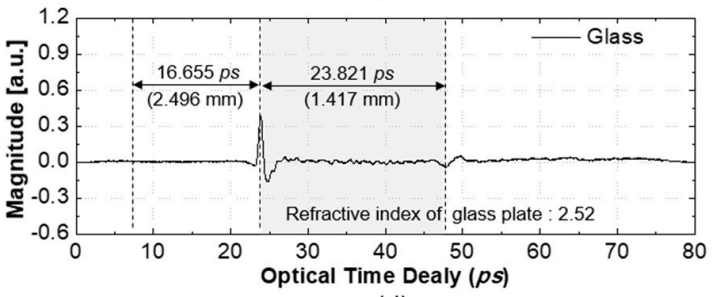

(d)

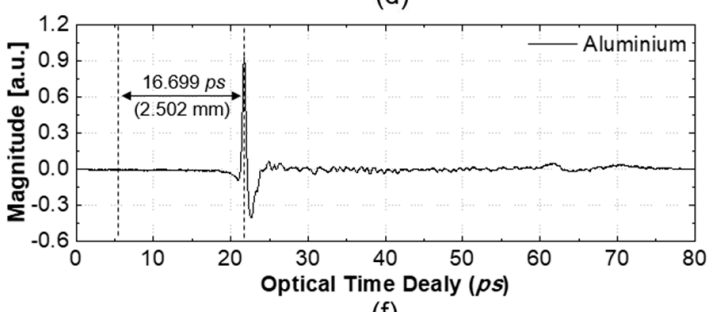

(f)

Figure 7. Measured Displacement and thickness according to the target materials: (a) thickness of the acrylic plate at zero position; (b) thickness and displacement of the acrylic plate at $2.5 \mathrm{~mm}$ pistons; (c) thickness of the glass plate at zero position; (d) thickness and displacement of the glass plate at $2.5 \mathrm{~mm}$ pistons; (e) a THz waveform of the aluminum plate at zero position; (f) displacement of the aluminum plate at the $2.5 \mathrm{~mm}$ position

\section{Conclusions}

In summary, we have reported a new approach for measuring the displacement and thickness of transparent materials. We have shown that it is possible to measure the displacement (distance) of both metallic and nonmetallic transparent samples with centimeter range and micrometer resolution. 
The results of the terahertz displacement and thickness sensor were compared with those of commercial laser displacement sensors and a thickness gauge. The results showed a displacement measurement range of $1 \mathrm{~cm}$ with less than $23 \mu \mathrm{m}$ error, and thickness measurement error of less than $8 \mu \mathrm{m}$. The errors of the measured displacement and thickness increased after $5 \mathrm{~mm}$ displacement due to the effective focal length of the TPX lens. This problem can be resolved by replacing the plano-convex lens with a longer focusing length.

The proposed terahertz displacement and thickness sensor has the following advantages: (1) non-contact measurement; (2) the ability to simultaneously measure the displacement and thickness of transparent samples, such as acrylic and glass plates; (3) the ability to measure the thickness of the individual layers of a multilayered sample; (4) the ability to provide thickness and displacement distribution maps for a sample, as well as single-point measurements.

When $\mathrm{THz}$ imaging performed, maintaining the focal length is an important factor. However, if we use this result, it can be performed without an additional distance sensor to keep the focal length between the THz sensor and sample surface.

Author Contributions: Conceptualization, D.-H.H.; formal analysis, D.-H.H.; project administration, L.-H.K.; resources, L.-H.K.; validation, D.-H.H.; Writing-Original draft, D.-H.H.; Writing—Review and editing, L.-H.K.

Funding: This material is based upon work supported by the Ministry of Trade, Industry \& Energy (MOTIE, Korea) under the Sensor Industry Enhancement Program (20003125, Development of an ultraprecision measurement sensor based on the fiber composite for flaw detection of the composite structure), and the Korea Institute for Advancement of Technology (P0007067).

Conflicts of Interest: The authors declare no conflict of interest.

\section{References}

1. O'Hara, J.F.; Singh, R.; Brener, I.; Smirnova, E.; Han, J.; Taylor, A.J.; Zhang, W. Thin-film sensing with planar terahertz metamaterials: Sensitivity and limitations. Opt. Express 2008, 16, 1786-1795. [CrossRef] [PubMed]

2. Strachan, C.J.; Rades, T.; Newnham, D.A.; Gordon, K.C.; Pepper, M.; Taday, P.F. Using terahertz pulsed spectroscopy to study crystallinity of pharmaceutical materials. Chem. Phys. Lett. 2004, 390, 20-24. [CrossRef]

3. Kemp, M.C.; Taday, P.F.; Cole, B.E.; Cluff, J.A.; Fitzgerald, A.J.; Tribe, W.R. Security applications of terahertz technology. In Terahertz for Military and Security Applications; International Society for Optics and Photonics: Washington, DC, USA, 2003; pp. 44-53.

4. Yang, X.; Zhao, X.; Yang, K.; Liu, Y.; Liu, Y.; Fu, W.; Luo, Y. Biomedical applications of terahertz spectroscopy and imaging. Trends Biotechnol. 2016, 34, 810-824. [CrossRef] [PubMed]

5. Yassin, S.; Su, K.; Lin, H.; Gladden, L.F.; Zeitler, J.A. Diffusion and swelling measurements in pharmaceutical powder compacts using terahertz pulsed imaging. J. Pharm. Sci. 2015, 104, 1658-1667. [CrossRef] [PubMed]

6. Hagelschuer, T.; Wienold, M.; Richter, H.; Schrottke, L.; Grahn, H.T.; Hübers, H.W. Real-time gas sensing based on optical feedback in a terahertz quantum-cascade laser. Opt. Express 2017, 25, 30203-30213. [CrossRef] [PubMed]

7. You, B.; Ho, C.H.; Zheng, W.J.; Lu, J.Y. Terahertz volatile gas sensing by using polymer microporous membranes. Opt. Express 2015, 23, 2048-2057. [CrossRef] [PubMed]

8. Lee, Y.S. Principles of Terahertz Science and Technology; Springer Science \& Business Media: Berlin, Germany, 2009.

9. Servagent, N.; Bosch, T.; Lescure, M. A laser displacement sensor using the self-mixing effect for modal analysis and defect detection. IEEE Trans. Instrum. Meas. 1997, 46, 847-850. [CrossRef]

10. Zhang, Z.; Feng, Q.; Gao, Z.; Kuang, C.; Fei, C.; Li, Z.; Ding, J. A new laser displacement sensor based on triangulation for gauge real-time measurement. Opt. Laser Technol. 2008, 40, 252-255. [CrossRef]

11. Nabavi, M.R.; Nihtianov, S.N. Design strategies for eddy-current displacement sensor systems: Review and recommendations. IEEE Sens. J. 2012, 12, 3346-3355. [CrossRef]

12. Wang, H.; Feng, Z. Ultrastable and highly sensitive eddy current displacement sensor using self-temperature compensation. Sens. Actuators A Phys. 2013, 203, 362-368. [CrossRef]

13. Baldwin, J.R.; Fox, M.D. Ultrasonic Displacement Sensor Using Digital Signal Processing Detection. U.S. Patent 7,027,355, 11 April 2006. 
14. Yin, W.; Peyton, A. Thickness measurement of non-magnetic plates using multi-frequency eddy current sensors. Ndt E Int. 2007, 40, 43-48. [CrossRef]

15. Dixon, S.; Edwards, C.; Palmer, S. High accuracy non-contact ultrasonic thickness gauging of aluminium sheet using electromagnetic acoustic transducers. Ultrasonics 2001, 39, 445-453. [CrossRef]

16. Yasui, T.; Yasuda, T.; Sawanaka, K.I.; Araki, T. Terahertz paintmeter for noncontact monitoring of thickness and drying progress in paint film. Appl. Opt. 2005, 44, 6849-6856. [CrossRef] [PubMed]

17. Yasuda, T.; Iwata, T.; Araki, T.; Yasui, T. Improvement of minimum paint film thickness for THz paint meters by multiple-regression analysis. Appl. Opt. 2007, 46, 7518-7526. [CrossRef] [PubMed]

18. Su, K.; Shen, Y.C.; Zeitler, J.A. Terahertz sensor for non-contact thickness and quality measurement of automobile paints of varying complexity. IEEE Trans. Terahertz Sci. Technol. 2017, 4, 432-439. [CrossRef]

19. Han, D.H.; Kang, L.H. Nondestructive evaluation of GFRP composite including multi-delamination using THz spectroscopy and imaging. Compos. Struct. 2018, 185, 161-175. [CrossRef]

20. Ens, J.; Lawrence, P. An investigation of methods for determining depth from focus. IEEE Trans. Pattern Anal. Mach. Intell. 1993, 15, 97-108. [CrossRef]

(C) 2019 by the authors. Licensee MDPI, Basel, Switzerland. This article is an open access article distributed under the terms and conditions of the Creative Commons Attribution (CC BY) license (http://creativecommons.org/licenses/by/4.0/). 